\title{
Motivation and Vision:
}

\section{A Survey of British Learners on the Mandarin Excellence Programme}

\author{
Qing Li ${ }^{1}$
}

\begin{abstract}
This study investigates learners' motivation and vision in learning Mandarin Chinese (hereafter Mandarin $^{2}$ ) as a second language in the UK context. Firstly, the current study aims to present the view of the learners' motivation and find out whether motivation differs between groups according to gender and the length of time studying Mandarin. Secondly, it further investigates the relationship between motivation and intended effort. Thirdly, this survey explores the role that vision played in motivation. In order to meet these aims, 40 participants from a secondary school located in London took part in this study. The participants were on the Mandarin Excellence Programme, which is a project that provides intensive Mandarin courses in secondary schools. The data was collected using a well-designed, six-point Likert scale questionnaire, which was based on the research literature on motivation of $L 2^{3}$ Mandarin and English learning. This study found that Chinese culture motivates participants the most in learning Mandarin and revealed significant correlations between motivation and intended effort. Furthermore, it found that cultural interest and travelling have a positive predictive effect on intended effort. In terms of vision, it proved that participants have developed vivid visualization in using Mandarin.
\end{abstract}

Keywords : Mandarin, motivation, vision, Mandarin Excellence Programme, Chinese culture

\section{Introduction}

As China is playing an important role on the international stage in the $21^{\text {st }}$ century, the interest in learning Mandarin as a second language has increased greatly. To exploit this trend and promote the Mandarin language and Chinese culture, China launched an ambitious project and established the non-profit Confucius Institute initiative in 2004, which aimed to provide various opportunities for learners from all over the world who want to learn about the Mandarin language. By 2019, 539 Confucius Institutes and 1,129 Confucius Classrooms have been established in a total of 155 countries around the world. Among them, there were29 Confucius Institutes and 148 Confucius Classrooms in the UK. In June 2012, the Institute of Education (IOE) Confucius Institute at University College London (UCL) was established. Until now, it has provided ongoing support to more than 45 IOE Confucius Classrooms, comprising over 9,000 students, as well as organizing the

\footnotetext{
${ }^{1} \mathrm{PhD}$ candidate in Culture, Communication and Media, University College London, Institute of Education, UK, email:qing.li.17@ucl.ac.uk

${ }^{2}$ In this dissertation, Chinese refers to entities such as people, roles, culture, society and institutions, while Mandarin refers to language.

${ }^{3}$ L2 refers to a language that a person acquires as his or her first language. In this specific context, it refers to Mandarin.
} 
largest Mandarin conference in the UK on a yearly basis. The IOE Confucius Institute also launched the Mandarin Excellence Programme (MEP) in 2016, one year after Chinese President Xi visited the UK in 2015. The MEP is a unique yet intensive language programme. Pupils involved in this programme are expected to spend an average of eight hours per week studying Mandarin over a period of four years, while the normal Mandarin classes are only two hours per week on average. As of 2019, 63 secondary schools had taken part in this programme.

The London secondary school involved in this empirical study joined the MEP in 2016, the year the programme was launched. I worked as a Mandarin teacher in the same secondary school before and witnessed the growing number of students who wanted to study Mandarin and their desire to be enrolled on this intensive and demanding Mandarin training programme. As a Mandarin teacher, I wondered what motivated them to learn Mandarin, which is a very different type of language compared with English and other European languages. Copious research has been conducted on learning English as a second language in different countries, while a few of studies have explored learning Mandarin as a second language (Liu, 2014),

\section{Literature Review}

\subsection{L2 motivational self-system and vision}

In the field of L2 language learning, motivation is believed to be the second most important index of success in second-language learning after aptitude (Skehan,1989; Gardner,1985; Dörnyei,2001; Dörnyei, 2003; Gardner, 2006; Gass and Selinker,2008) and generally understood in terms of the willingness to begin learning a L2 language and the commitment shown in order to keep learning it (Ortega,2009). Dörnyei (2005) observed that motivation serves as a primary impetus and a driving force for learners to start L2 learning and sustain the learning process. Dörnyei then proposed a new approach to investigate motivation in 2005 , which has been considered as the most promising approach in the field of L2 motivation within a 'self' framework (Csizer and Kormos, 2009; MacIntyre et al.,2009; Ortega, 2009; Taguchi et al.,2009). This 'self' framework was mainly informed by Higgins' (1987) self-discrepancy theory, which pointed out that people are motivated to reduce the inconsistency between one's ideal and actual selves in order to become their ideal self (Higgins, 1987).This conceptualization led Dörnyei to propose the L2 motivational self system, as he observed thatL2 learners are motivated to reduce the gap between the ideal and actual selves when learning and speaking a second language(Dörnyei, 2005).Apart from the theoretical basis, a series of empirical studies also influenced the development of this motivational self-system. Conducted in Hungary in 1993, 1999 and 2004, the stratified national study of L2 learning motivation got involved with 13,000 L2 learners of English, German, French, Italian and Russian. This largest-ever L2 motivation study laid a solid foundation for Dörnyei’s self-system work, which is constructed around three primary components:

(1) Ideal L2 self. This 'concerns a desirable self-image of the kind of L2 user one would ideally like to become in the future' (You and Dörnyei, 2016), which reflects the individual's vision of being an effective L2 user (Dörnyei and Ushioda, 2011). An example in this case would be that I can imagine myself as someone who is able to speak Mandarin fluently. The ideal L2 self is regarded as the most powerful motive in one's L2 learning process, as the unease caused by the discrepancy between one's actual and ideal self-image will act as a potent motivation source and has a more direct relationship with motivated behavior'(Ryan, 2009, p.137). 
(2) Ought-to L2 self. This concerns the imported self-image such as when someone believes that they should possess certain attributes to meet others' expectations and avoid possible negative outcomes. For instance, I consider learning Mandarin important because the people I respect think that I should do it. This is less powerful than the ideal L2 self as it refers to external factors instead of being generated from learners' inner desires.

(3) L2 learning experience. This is a motivation that is associated experiencing the immediate learning environment, in terms of the influence of the teacher, the curriculum, peer groups or how success is felt (Dörnyei, 2009.). For example, I think time passes faster while studying Mandarin. Unlike the first two components, which derived directly from self-discrepancy, L2 learning experience is conceptualized at a different level.

Within this model, the three components in the L2 motivational self-system are not completely independent of each other (e.g., Papi, 2010; Taguchi, 2013; Taguchi et al., 2009). The learning experience affects future images of individual's self and the imagined future possible selfalso projects onto reality and has an effect on the learning experience (Dörnyei and Chan, 2013).

Apart from the inter-relation between the three components, another important feature of this model is concerned with the dynamic nature of future possible selves. As early as 2005, Dörnyei noted that the future self-guides (i.e., ideal L2 self and ought-to L2 self) involve mental images, which are neural representations of an individual's imagination (You et al., 2016). You and Chan (2015) suggested that mental imagery related to an individual's future self is always subject to change during the L2 learning process in terms of its content, elaborateness, and frequency. For example, the ideal L2 self may be different after the completion of a task, while the individual may also reset their goal to ease the inconvenience caused by the gap between the actual self and ideal self. When imagery is associated with ensuing behaviour, it is understood as vision (You et al., 2016). Dörnyei and Kubanyiova (2014) pointed out, vision offers a broad view to explore the overall commitment needed to successfully learn a language as vision particularly involves a vivid mental image, which depicts a desired future status. Visualization capacity is 'an individual's capacity of forming vivid, controllable images and retaining them for sufficient time to effect the desired imagery rehearsal' (Morris, 1997, p. 37). Visualization capacity is usually measured by vividness of imagery (Morris, Spittle and Watt, 2005). Dörnyei and Kubanyiova (2014) explained that, without being able to produce intense imagery during visualization, a desirable self-image may be ineffective in motivating someone into action. A typical example for this is I can usually have both vivid mental pictures and/or sounds of situations when I'm imagining myself using Mandarin skillfully in the future. Mental imagery is greatly stimulated by senses, which includes sight, touch, taste, sound and smell (Kosslyn, Thompson and Ganis, 2006). In the field of L2 language learning, mental imagery is typically associated with sight and sound, which closely connect with the two main learning styles: visual and auditory style (You et al., 2016; Dörnyei and Chan,2013).

\subsection{Main research findings on motivation in second-language learning Major studies on L2 English}

Since the L2 motivational self-system was proposed at the beginning of the 21 stcentury, it has attracted a great deal of attention from researchers, who have gone onto test and validate its values in various countries and context (e.g., Csizer and Kormos, 2009; Taguchi et al., 2009; Ryan, 2009; Lamb, 2009; Kim, 2009). Taguchi et al. (2009) noted that there is certain connection between the 
L2 motivational self-system and the socio-education model, which was the first L2 motivational framework proposed by Gardner and Smythe (1975). In that model, L2 motivation contains three main factors: integrativeness, instrumentality and attitude towards the learning situation (e.g., teachers, classmates, the course materials). Integrative motivation reflects a strong desire to learn another language and communicate with it in order to engage with others from the target language population (Gardner and Lambert, 1972). Instrumentality motivation refers to learning a second language for more practical reasons, such as to get a job. However, instrumental motivation is not considered as significant as integrative motivation in the index of learners' motivation (Gardner, 2001). Dörnyei $(2005,2009)$ proposed that the traditional promotional instrumentality exerts a pulling power when learning a second language to facilitate professional development, whereas prevention instrumentality has an avoidance focus, such as when studying a second language in order not to fail a course or disappoint others. The distinction between these two kinds of instrumentality is important as promotional instrumentality relates to the ideal L2 self and prevention instrumentality relates to the ought-to L2 self (Dörnyei and Chan, 2013).Csizer and Kormos carried out a study on motivation towards L2 English among secondary school and university students in Hungary. It found that ideal L2 self and L2 learning experience were almost equally important in students learning behaviour, while ought-to L2 self was a weaker contributor. Furthermore, L2 learning experience exercised more importance for secondary school learners (Csizer and Kormos, 2009). Conducted in Japan, China and Iran, Taguchi et al.'s (2009) study, revealed that ideal L2 self, better predicts intended efforts compared with other motivations.

Recently, the number of studies on motivation and vision has been growing, especially in terms of future L2 self-guides, visualization capacity, learning styles and motivated L2 behaviour. To investigate motivation and vision, Dörnyei and Chan (2013) conducted a survey among 172 Year 8 Chinese students of L2 English. This survey confirmed that ought-to L2 self was not as energizing as ideal L2 self. It also revealed a significant correlation between future self-guides and intended effort. Furthermore, the imagery capacity was especially reflected in participants' future self-guides. By investigating secondary schools and university students, AI-Shehri (2009) found a highly correlation between imagination, the ideal L2 self and motivated performance. Meanwhile, Kim (2009b) conducted a survey in primary schools in Korea and discovered that the auditory learning style is significantly related to imagination, the ideal L2 self and motivated behaviour. Later, Kim and Kim (2011) expanded this research by involving secondary school students, revealing visual and auditory learning preferences and visual capacity play key roles in the formation of a vivid ideal L2 self. By applying mixed methods, You and Chan (2015) revealed that motivation makes a great deal of difference between students who engaged in the visualization as L2 users and those who did not. Other studies have also suggested a positive correlation between visualization and motivation, that is to say, increased in visualization usually results in improved motivation after purposeful training (e.g., Chan, 2014; Mackay, 2014; Magid, 2014; Sampson, 2012). However, it was not until 2016 that a full and robust model integrating vision and motivation was constructed by You, Dörnyei and Csizer, as presented in Figure 1 below. The right side of this model shows the L2 motivation self-system and intended effort. You et al. (2016) found out that the ideal L2 self, ought-to L2 self and L2 learning experience significantly predict intended effort. The left side of this model shows the relationship between vision-specific variables and the L2 motivational self-system. Visual and auditory styles are generally understood as having connection with L2 
learning experience (Dörnyei and Chan, 2013). Indeed, the more visual or auditory skills students develop, the more successful they are in L2 learning, and thus the more they enjoy the learning experience in classroom (You et al., 2016). Visual style and auditory style are also believed to naturally connect with vividness of imagery, as it is through them that imagery is generated (Dörnyei and Chan, 2013). The system represents an overarching model with which to explain how motivation specifically relates to language learning (Ortega, 2009).

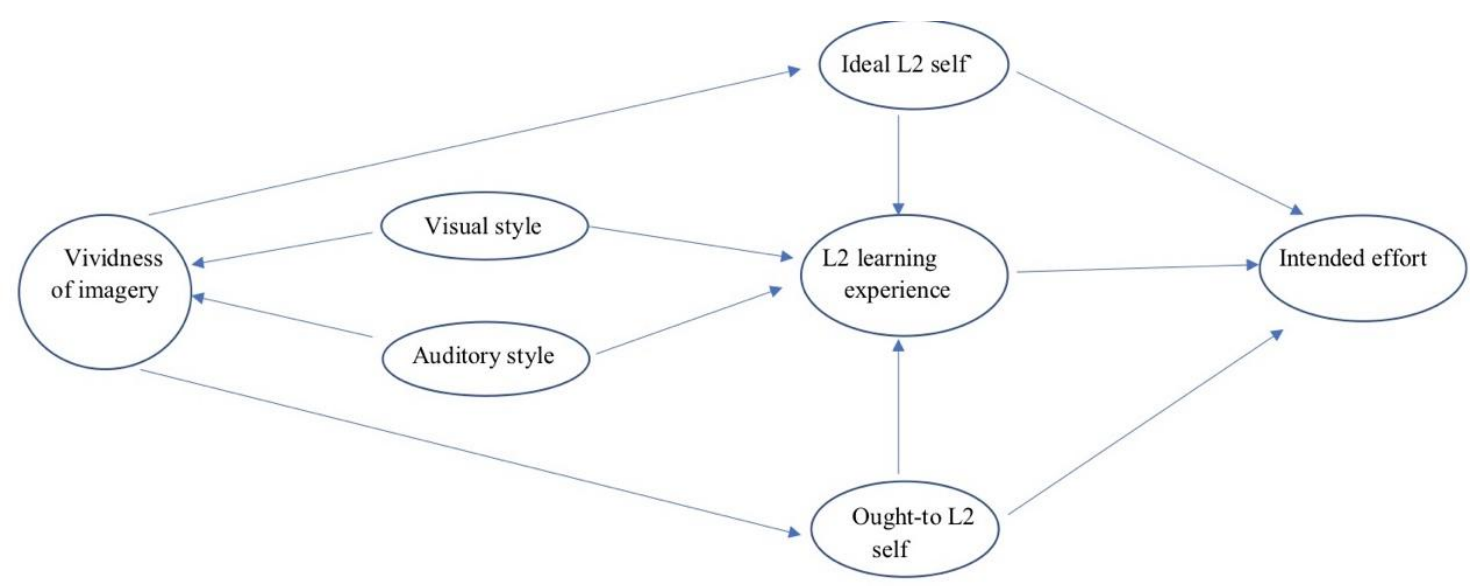

Figure 1 Full Structural Model (You, Dörnyei and Csizer, 2016)

\section{Major studies on L2 Mandarin}

Though studies of L2 Mandarin learning have only started to flourish, it is worthy introducing some of the main findings in the L2 Mandarin context. Wen (1997) conducted a survey amongst university students in America, who were from Asian or Asian American families. The results revealed that these learners were mostly motivated by Chinese culture. Yu (2009) compared the motivation towards L2 Mandarin learning among 151 Australian university students and towardsL2 English learning among 344 Chinese university students. By comparing the results from both countries, it revealed that Chinese students' motivation towards learning English was more instrumentality oriented (e.g. to improve their career or academic opportunities in future), while Australian students of L2 Mandarin were more likely motivated in terms of integrativeness (e.g. to communicate with Chinese native speakers). It also revealed that there was a significant correlation between their L2 language motivations andL2 language achievements. Wen (2013) explored the relationship between motivation and the language learning environment, as well as ethnicity, and language proficiency. The study revealed that instrumentality and L2 learning experience were the strongest forms of motivation among beginners and intermediate learners, while self-confidence was the strongest predictor for advanced learners. Using a mixed-methods approach, Liu (2014) conducted a survey among 130 university-level L2 Mandarin learners involving the L2 motivational self-system. The results confirmed the effectiveness of these lf system in L2 Mandarin and revealed some significant correlations: the ideal L2 self, had a stronger explanatory power towards intended efforts than other types of motivation; the ideal 12 self significantly correlated with promotional instrumentality; and the ought-to L2 self-had a stronger correlation with prevention instrumentality than promotional instrumentality. 


\subsection{Research questions}

This study investigates students' motivation towards learning Mandarin as a second language in the UK, as well as further explores the role of vision played in L2 Mandarin motivation. Specifically, in this study, the questions concerning motivation and vision are:

1. What does students' motivation look like in the context of learning Mandarin as a second language in the UK? What does motivation look like between groups according to year (7/8) and gender?

2. What are the relationships between motivation and intended effort? To what extent does motivation contribute to participants' intended effort?

3. Have L2 Mandarin learners ever engaged in the visualization of using Mandarin? If they have, does vision make a difference to the L2 motivational self-system between the vision-yes and vision-no groups?

4. What is the relationship between vision-specific variables (i.e., vividness of imagery, visual style and auditory style) and L2 motivational self-system among the vision-yes group?

\section{Methodology and Data Sources}

\section{Participants}

Participants in this study are Mandarin students $(n=40)$ in Year $7(n=20)$ and Year $8(n=20)$. All of them are from the same secondary school in the north of London in the UK, where Mandarin is a compulsory subject for all Year 7 students but an option from Year 8 onwards. The participants in this study are all enrolled on the MEP.

\section{Instrument}

The instrument used in this study is an anonymous questionnaire composed of three parts. The first part concerns the motivation domain and contains 30 six-point Likert scale question items. The second part concerns vision domain and contains 12 six-point Likert scale question items. The third part concerns background information and contains seven questions such as gender, nationality and length of learning Mandarin.

The variables in the motivation domain are ideal L2 self (e.g., I can imagine myself as someone who is able to speak Mandarin fluently), cultural interest (e.g., I would like to know more about people from China), traveling (e.g., I would like to travel to Mandarin-speaking countries or areas), instrumentality (promotion)(e.g., Studying Mandarin may be important to me because I think I'll need it will someday to get a good job and/or make money.), ought-to L2 self (e.g., I consider learning Mandarin important because the people I respect think that I should do it.), family influence (e.g., My parents encourage me to practice my Mandarin as much as possible) and instrumentality (prevention) (e.g., Studying Mandarin is important to me, because I would feel ashamed if I got bad grades in Mandarin), L2 learning experience (e.g., I think time passes faster while studying Mandarin) and intended efforts (e.g., I am prepared to expend a lot of effort in learning Mandarin). The questions in this selection are mainly based on You and Dörnyei's (2016) investigation and Dörnyei (2010), which have been broadly applied to surveys on motivation in L2 learning. Each variable covers three to four question items (see Table 1). All question items included are considered as being the most typical question items for the purpose of this study. 
The vision part mainly contains vision-specific variables, which are vividness of imagery (e.g., I can have several vivid mental pictures and/or sounds of situations when I'm imagining myself using Mandarin skillfully in the future), visual style (e.g., When I listen to a teacher, I imagine pictures, numbers or words) and auditory style (e.g., I remember things I have heard in class better than things I have read). Each variable covers four question items. This is an optional part and supposed to be answered by those who experience visualizing the use L2 Mandarin. Therefore, it separates students into two groups: vision-yes group and vision-no group. It is introduced by the following: Have you ever imagined yourself using Mandarin in the future when you have learned it? If so, please answer the next few questions. If not, please go to Part 3. TTable2 gives a brief introduction to the question items.

\section{Data collection procedure}

Data was collected at the end of the academic year. The consent forms were voluntarily signed by the students and agreed by their parents/guardians for their participation. The process of answering the questionnaires was conducted at the beginning of two Mandarin classes (one for Year 7 and one for Year 8), which took about 10 to 15 minutes.

\section{Data analysis}

Data was first input into Microsoft Excel and organized according to the category of variables. For each participant, the scores for all the question items in the same variable were added and then divided by the number of items. Therefore, an average score was determined for each participant in the case of each variable. The results were then converted to and analysed by SPSS 25.0. The consistency reliability coefficients of the variables from the results of all the questionnaires were above the threshold 0.70 .

\section{Results}

\subsection{Motivation domain: general findings and findings broken down by year and gender General findings}

In the whole sample, the mean values vary from 3.14 to 5.26 (table 1). Seven out of nine motivation variables exceed the midpoint of 3.50. Cultural interest as the highest mean value $(M=5.26)$ among all motivation variables. The second factors are instrumentality (promotion) and travelling $(M=5.11)$, followed by the ideal L2 self $(M=4.56)$ and $L 2$ learning experience $(M=4.60)$. The figures for intended effort $(\mathrm{M}=4.92)$, suggests a strong commitment towards making efforts in this L2 language. Family influence is also a relatively high motivation $(\mathrm{M}=4.41)$.Obviously, the two lowest mean values fall on instrumentality (prevention) $(\mathrm{M}=3.14)$ and ought-to L2 self $(\mathrm{M}=3.43)$. 
Table 1: Motivational Variables

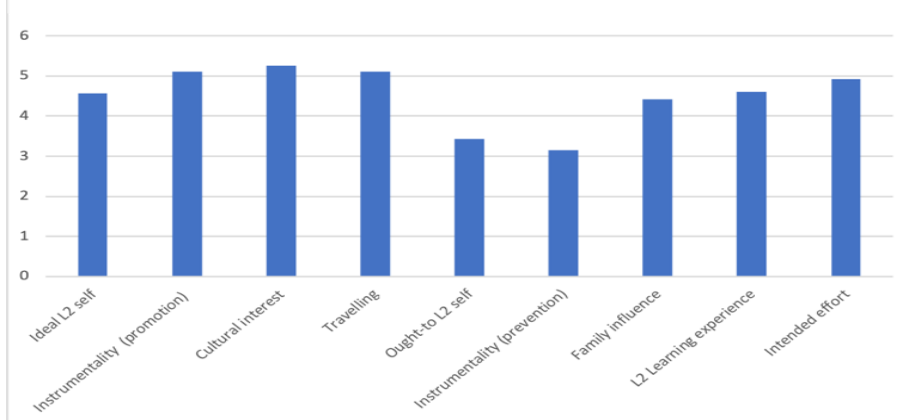

\section{Motivation findings broken down by year}

As can be seen from Table 2, the figures for Year 7 range from 2.95 to 5.33 and Year 8 from 3.33 to 5.20. From both groups, the strongest motivations are still cultural interest and the weakest motivations are Instrumentality (prevention) and ought-to L2 self, which are in line with the whole sample. To find out whether there is a significant difference between Year 7 and Year 8 in all motivation variables, an independent-samples $\mathrm{T}$ test was performed. The result showed that there was a significant difference for ideal L2 self in the scores for Year $7(\mathrm{M}=4.86, \mathrm{SD}=0.69)$ and Year $8(\mathrm{M}=4.27, \mathrm{SD}=0.96)$ conditions; $\mathrm{t}(34.442)=2.239, \mathrm{p}=.032$. Concerning L2 learning experience, there was a significant difference for the Year $7(\mathrm{M}=4.98, \mathrm{SD}=0.92)$ and Year $8(\mathrm{M}=4.23, \mathrm{SD}=1.09)$ conditions: $\mathrm{t}(38)=2.342, \mathrm{p}=.025$. For intended effort, there was also a significant difference in the scores for the Year $7(\mathrm{M}=5.21, \mathrm{SD}=0.67)$ and Year $8(\mathrm{M}=4.64, \mathrm{SD}=0.88)$ conditions: $\mathrm{t}(37)=2.299$, $\mathrm{p}=.027$. Therefore, we can conclude that the duration of learning Mandarin does have significant effect on ideal L2 self, L2 learning experience and intended effort but it does not make a difference in the case of other types of motivation.

Table 2 Group Statistics

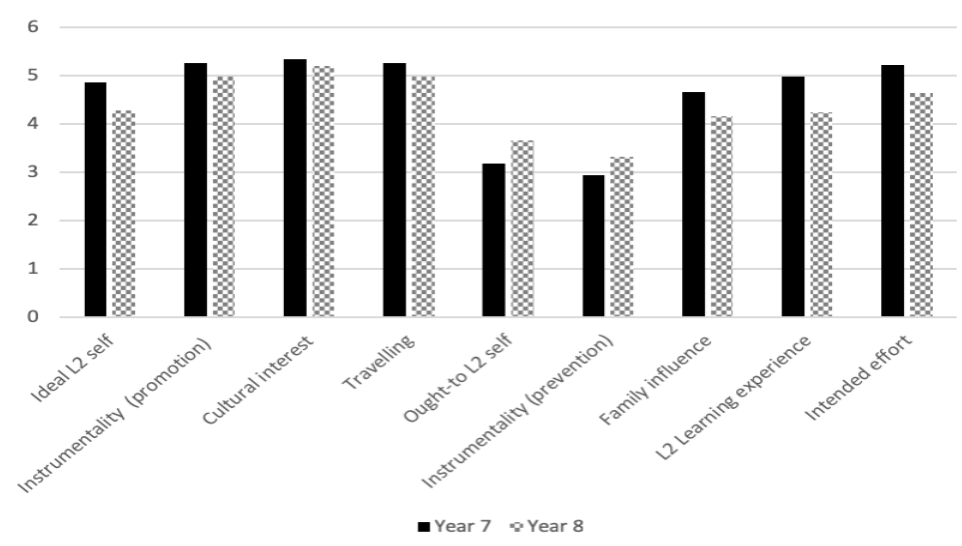




\section{Motivation findings by gender}

In this study of 40 students, there are 12 males and 22 females, with six students choosing not to indicate their gender. As Table 3 shows, apart from travelling and L2 learning experience, males exceed females for the remaining motives. The independent-samples $\mathrm{T}$ test found that there was a significant difference for ought-to $\mathrm{L} 2$ self in the scores for male $(\mathrm{M}=4.01, \mathrm{SD}=0.98)$ and female $(\mathrm{M}=3.00, \mathrm{SD}=0.93)$ conditions; $\mathrm{t}(34)=3.116, \mathrm{p}=.004$. Another significance difference was noted for family influence in the scores for male $(\mathrm{M}=4.86, \mathrm{SD}=0.69)$ and female $(\mathrm{M}=4.12, \mathrm{SD}=1.04)$ conditions; $\mathrm{t}(33)=2.336, \mathrm{p}=0.026$. Therefore, gender does make significant difference on ought-to L2 self and family influence.

Table 3 Groups Statistics

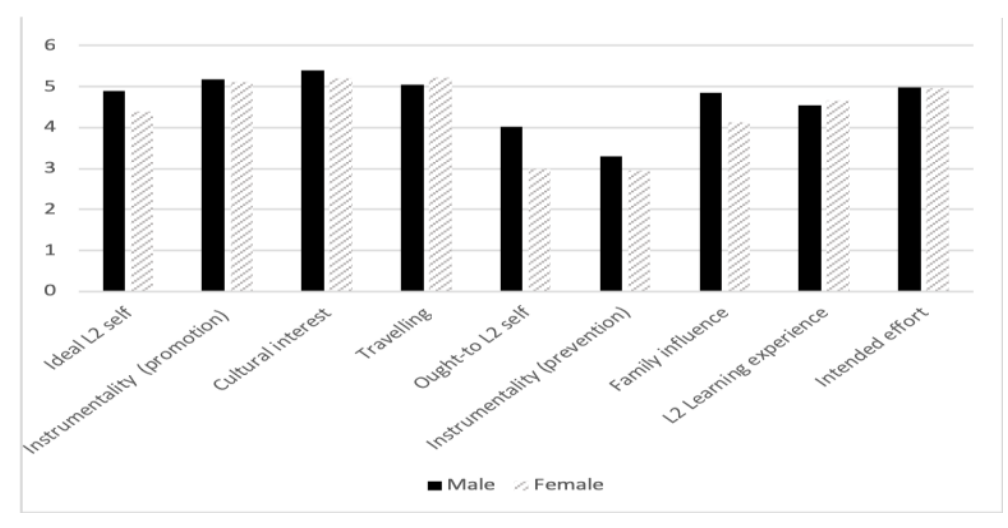

\subsection{Significance of motivation}

The question most concerned with motivation in L2 learning is always about how it can reflect actual learning behaviours (You and Dörnyei, 2016). Research in this field usually examines the correlation between motivation variables and intended effort, that is, how much effort given by L2 learners to learning an L2 language is affected by motivation variables. The results of Pearson correlation performed in this study suggest that six out of eight correlations between motivation variables and intended effort are statistically significant, namely, cultural interest $(\mathrm{r}(39)=+.593$, $\left.\mathrm{p}<0.001^{4}\right)$, ideal L2 self $(\mathrm{r}(39)=+.578, \mathrm{p}<0.001)$, instrumentality (promotion) $(\mathrm{r}(39)=+.567$, $\mathrm{p}<0.001)$, L2 learning experience $(\mathrm{r}(39)=0.564, \mathrm{p}<0.001)$, travelling $(\mathrm{r}(39)=+.711, \mathrm{p}<0.001)$, and family influence $(\mathrm{r}(39)=+.401, \mathrm{p}<0.05)$. Family influence is significantly correlated but plays a relatively moderate role in the correlation with intended effort. Conversely, ought-to L2 self $(\mathrm{r}(39)=-.147, \mathrm{p}=0.371)$ and instrumentality (prevention) $(\mathrm{r}(39)=-.254, \mathrm{p}=0.119)$ have no significant correlation with participants' intended effort. However, correlation is not an indication of a cause-and-effect relationship. In order to calculate to what extent each variable predicts participants' 
intended effort, a multiple linear regression was performed. According to the results, this model indicates that $79.1 \%$ of the variations can be explained. The Durbin-Watson statistic is 1.909 , which is very close to 2.00 and suggests that this model is well constructed. The significance value of .000 attained in the ANOVA further confirms that the model is a good significant predictor. A significant regression equation was found $(\mathrm{F}(8,29)=10.958, \mathrm{p}=.000)$, with an $\mathrm{R}^{2}$ of .791 . Participants' intended effort is equal to $.175+.341 *$ cultural interest $+.416 *$ travelling $-.239 *$ instrumentality (prevention). The most affective variable is travelling and cultural interest, which suggests that, when the other variables are held, a one-unit increase in travelling and cultural interest will result in an increase of .416 and .341 respectively in intended effort. Conversely, a one-unit increase in instrumentality (prevention) leads to a decrease of .239 in intended effort. Other variables offer no prediction of participants' intended effort.

\subsection{Vision domain: significance of vision}

As discussed before, those who chose to answer the optional part in the vision domain were those who have developed the ability to visualize the use of L2 Mandarin and hence were assigned to the vision-yes group.

As can be seen from Table 4, the vision-yes group $(\mathrm{N}=33)$ has a higher score than the vision-no group $(\mathrm{N}=7)$ for two out of the three variables (i.e., ideal L2 self and L2 learning experience). The result of the independent-samples $\mathrm{T}$ test shows a significant difference in the L2 learning experience in the scores for the vision-yes $(\mathrm{M}=4.86, \mathrm{SD}=0.98, \mathrm{n}=33)$ and vision-no $(\mathrm{M}=3.64$ $\mathrm{SD}=1.03, \mathrm{n}=7)$ groups; $\mathrm{t}(38)=2.832, \mathrm{p}=.007<.05$. However, vision does not make any significant differences in the case of ideal L2 self and ought-to L2 self.

Table 4 Group Statistics by Comparing the Motivational Variables in the Vision-yes and Vision-no

Subgroups

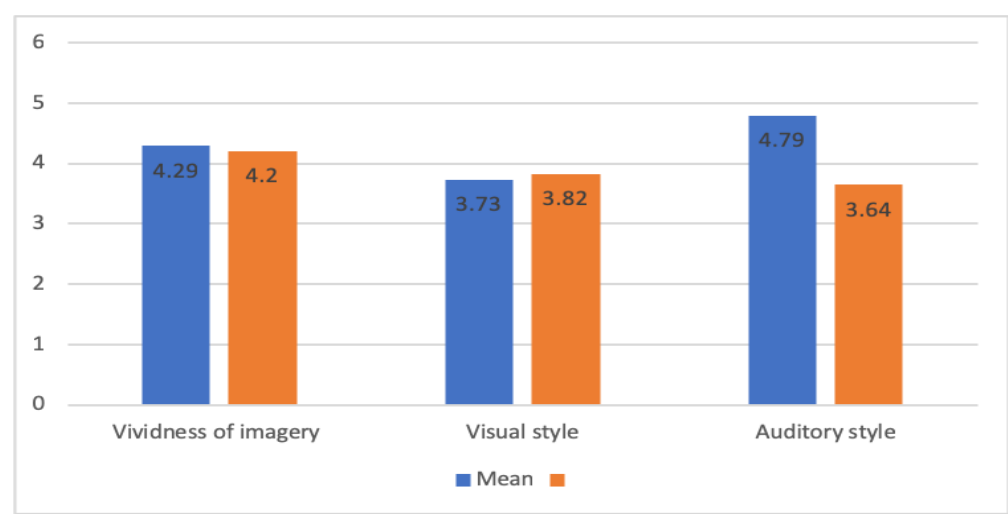

\subsection{Roles of vision-specific variables in motivation}

Among those who experienced the visualization of using Mandarin, the mean scores for vision-specific variables (i.e., vividness of imagery, visual style and auditory style) exceeded the mid-point (Table 5). Specifically, the figure for vividness of imagery is 4.29 , which suggests a strong visualization capacity. Interestingly, the mean value for auditory style $(\mathrm{M}=4.79)$ is much higher than visual style $(\mathrm{M}=3.73)$. This indicates a tendency that participants prefer auditory styles over visual styles in learning, which could also explain the phenomenon whereby learners always pick up Mandarin pronunciation faster and easier, compared with remembering and recognizing Mandarin words. However, no significant correlation was found between vision-specific variables 
and the L2 motivational self-system. Table 5 Descriptive Statistics of Vision-specific Variables

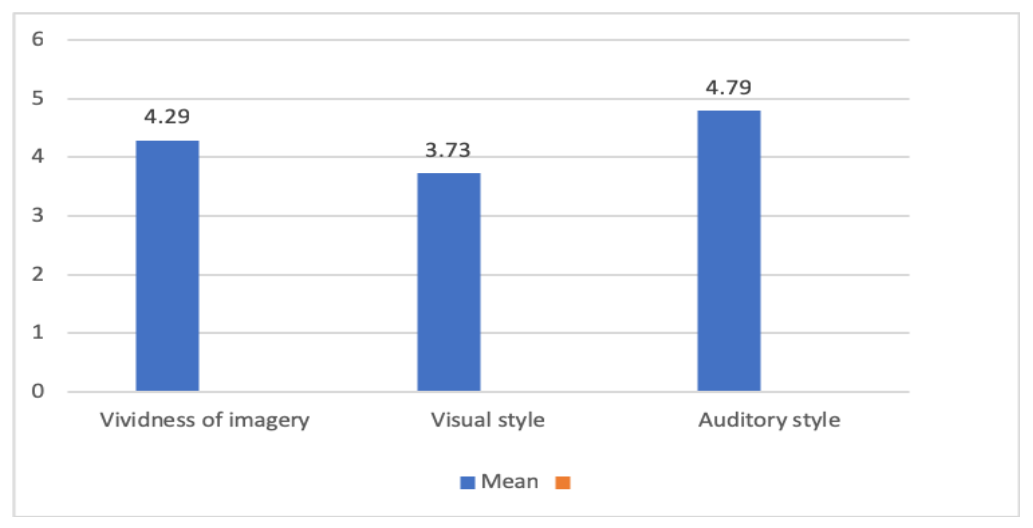

\section{Discussion}

\subsection{Answering questions}

Question 1: What does students' motivation look like in the context of learning Mandarin as a second language in the UK? What does motivation look like between groups according to year (Years 7/8) and gender?

The results show that students are highly motivated towards learning Mandarin as seven out of nine motivation variables exceed the midpoint (3.50), apart from ought-to L2 self and instrumentality (prevention). (1) amongst all the motivation variables, cultural interest is the most attractive factor for participants $(M=5.26)$. Wen's study (1997), conducted among university students from Asian and Asian American families, also reported that the interest in Chinese culture motivated learners the most. (2) Ideal L2 self ( $M=4.56)$ and L2 learning experience ( $=4.60)$ play important roles in learners' motivation. Interestingly, the mean scores for both are very close in this study. Similarly, Csizer and Kormos's (2009) study also found that ideal L2 self and L2 learning experience were almost equally important regarding secondary schools learners' motivation towards L2 English in Hungary. Wen's (2013) study revealed that L2 learning experience highly motivated American students' Mandarin learning. (3) The mean values for ought-to L2 self and instrumentality (prevention) are the lowest, which indicates that UK learners are less compelled and personally choose to pursue L2 Mandarin learning. A closer look at ideal L2 self and ought-to L2 self, reveals that the mean values for the former are much higher than those for the latter, which has been considered to be a general tendency in L2 language learning (Dörnyei and Chan., 2013; Liu, 2014; You and Dörnyei., 2016).

(1) In terms of the findings broken down by year, significant differences were found for ideal L2 self, intended effort and L2 learning experience between Year 7 and Year 8. That is, Year 8 show a less ideal L2 self, positive experience and intended effort than Year 7 in using Mandarin.

(2) In terms of the motivation difference between males and females, the results show that the mean values for males $(\mathrm{N}=14)$ exceeded those for females $(\mathrm{N}=22)$ in the case of seven motivation variables, apart from travelling and L2 learning experience. Significant differences between males and females can be observed for ought-to L2 self and family 
influence, where males exceed females. Conversely, most of the research on L2 language learning shows an opposite tendency in terms of gender difference. Henry (2010) proposed that the core difference between males and females is that females show more interdependency during and commitment to interpersonal interaction than males. Therefore, females are more likely to invest in self-other relationships. Henry and Cliffordson (2013) further explained that females view their involvement in communication as being much easier than males, which in turn shapes their motivational future self-guides. That is to say, in terms of L2 language learning motivation, females are supposed to be motivated more than males. A large-scale survey of L2 English learners conducted in Chinese secondary schools also revealed the tendency that female learners are more motivated than males (You and Dörnyei, 2016). However, the results of this study pointed to an opposite phenomenon where males are more motivated than females for most of these motivation variables. Just as Henry (2010) suggested that further surveys should be conducted in different contexts to test his own speculations, this L2 Mandarin-specific feature also needs to be investigated in more detail in future.

\section{Question 2: What are the relationships between motivation variables and intended effort? To} what extent does motivation contribute to participants' intended effort in learning Mandarin? This survey found out that ideal L2 self, instrumentality (promotion), cultural interest, travelling and L2 learning experience have significant correlations with intended effort. Family influence also significantly correlates with intended effort but plays a relatively moderate role. Meanwhile, according to a survey of L2 English learning conducted in China (You and Chen,2016; Chen et al., 2005), Chinese L2 English learners showed that there was a strong correlation between intended effort and family influence. Therefore, Chinese learners of L2 English face more external pressure than UK learners of L2 Mandarin. This is in accordance with the striking contrast between ideal L2 self and ought-to L2 self in terms of the correlation with intended effort. Similarly, Yu's (2009) study, which compared the Australian learners of L2 Mandarin and Chinese learners of L2 English, revealed that Australian leaners were more motived by internal interests than Chinese learners in L2 language learning.

The results of regression further revealed that cultural interest, travelling and instrumentality (prevention) have a significant prediction effect in terms of intended effort $(\mathrm{p}<.05)$. Participants' intended effort is equal to $.175+.341 *$ cultural interest $+.416 *$ travelling $-.239 *$ instrumentality (prevention).

Question 3: Have L2 Mandarin learners engaged in the visualization of using Mandarin? If they have, does vision make a difference to the L2 motivational self-system between the vision-yes and vision-no groups?

This survey found that the majority of the participants have already developed vision in L2 Mandarin learning as the numbers of participants in the vision-yes group $(\mathrm{N}=33)$ outnumbers those in the vision-no group $(\mathrm{N}=7)$. The independent-samples $\mathrm{T}$ test proved that vision does have a statistical difference concerning L2 learning experience between the vision-yes and vision-no groups but no significant difference for ideal L2 self and ought-to L2 self. A general trend whereby most L2 learners from secondary schools have developed visualization in an L2 language has been 
confirmed by Dörnyei and Chan (2013) and Chan (2015), which further revealed that the vision-yes group scored higher than the vision-no group in terms of ideal L2 self and L2 learning experience.

Question 4: What is the relationship between vision-specific variables (i.e., vividness of imagery, visual style and auditory style) and $\mathrm{L} 2$ motivational self system among the vision-yes group?

According to the analysis, the mean values for vision-specific variables exceeded the midpoint, which means that the participants have developed vivid visualization. The figures for auditory style $(\mathrm{M}=4.79)$ exceed those for visual style ( $\mathrm{M}=3.73)$, which could explain why speaking and listening are always easier than reading when the students acquire such skills. However, considering that the number of participants is small, this inference needs to be further confirmed. In the survey conducted by You et al. (2016), significant correlations were found between vision-specific variables and the L2 motivational self-system. However, no correlation between vision-specific variables and the system was found in this study.

\subsection{Overall limitations and suggestions for further study}

Due to the current nature of the MEP, this study was only able to investigate the participants who have studied Mandarin for one or two years. More dynamic changes in motivation and vision could be found in future along with the development of this programme. This study only used a questionnaire to collect data. Although general findings were produced using quantitative methodology to some extent, this study was limited in terms of investigating the reasons such as why the participants are highly motivated by travelling in China and why Year 8 are less motivated than Year 7. Based on the limitations discussed above, this study can be mainly expanded in the following respects:

\section{(1) Samples}

On the one hand, focusing on MEP students offers some advantages in research as they all attend the same school, follow the same Mandarin curriculum and are taught by the same teachers. On the other hand, these MEP students are at a relatively higher level of L2 Mandarin than the non-MEP students. It would be interesting to investigate what non-MEP students' motivation looks like and whether they have experienced the visualization of using L2 Mandarin. Therefore, a comparison between the MEP and non-MEP groups would provide a more comprehensive view of motivation towards L2 Mandarin among students from UK secondary schools.

\section{(2) Time}

It would be productive to conduct this survey on repeated basis at different times to find out whether there are significant changes in motivation and vision during the whole learning process, as well as further identify general trends concerning such changes.

\section{(3) Methodology}

Qualitative methods such as interviewing are recommended for gathering data in more details (Johnson and Onwuegbuzie, 2004) such as the reason why Year 8 students experienced less fun in their L2 learning experience than Year 7. Further research could also be considered in which intended effort is replaced with the actual results of Mandarin language tests, in order to find out to what extent motivation might affect students' actual achievement. 


\section{Conclusion}

By conducting the survey among 40 students on MEP from a secondary school in London, this study presented a profound insight into motivation and vision in L2 Mandarin learning. The participant learners are highly motivated and intend to make great efforts towards learning Mandarin. The attraction of Chinese culture is the strongest reason given for learning Mandarin, followed by wishing to travel to China, personal development (instrumentality promotion) and L2 learning experience. A striking contrast was noted between ideal L2 self and ought-to L2 self. The latter, which is less internalized by learners, has a less powerful influence on learners' motivation. It was further revealed that cultural interest and travelling positively predicts participants' intended effort, while instrumentality prevention has a negative prediction effect. Among the participants in this study, Year 7 learners scored significantly higher than those in Year 8 on ideal L2 self, L2 learning experience and intended effort. Males scored significantly higher than females on ought-to L2 self and family influence. In vision domain, this study revealed that, although the learners in the study were only in their first or second year of learning Mandarin, most of them have already visualized speaking/using the language. Having visualization experience makes a significant difference to L2 learning experience, given that those who are able to visualize the use of Mandarin have a better experience of learning it. In general, this study shared features that have been characteristics of the majority of other studies. For example, the contrast between ideal L2 self and ought-to L2 self is striking as ideal L2 self is much stronger than ought-to L2 self (Ryan, 2009; Dörnyei and Chan, 2013; You and Dörnyei., 2016). Meanwhile, gender makes a differences to motivation (Henry and Cliffordson, 2013; You et al., 2016) and the majority of the participants have engaged in vision and experienced changes in this regard (Dörnyei and Chan, 2013; Chan, 2015; You et al., 2016). However, this study also revealed certain unique traits as follows: instrumentality (promotion) is stronger than ideal L2 self; males' motivation in L2 Mandarin is significantly stronger than that of females; future self-guidance has no prediction effect in terms of intended effort; vision only makes a significant difference to L2 learning experience but not ideal L2 self and ought-to L2 self; no significant correlation has been found between vision-specific variables and the L2 motivational self-system.

Theoretically, it is the first study on L2 Mandarin motivation to be conducted in the context of the MEP in the UK. Although this study is a small-scale study, it makes a small but profound step towards expanding the research scope for L2 Mandarin motivation. This study is also one of the few studies to have applied Dörnyei's L2 motivational self-system in the context of L2 Mandarin learning. To some aspects, the results are comparable to the results of previous studies on this system conducted in the context of L2 English. Most importantly, they revealed that, although the L2 Mandarin learners had only been learning the language for one or two years, they are highly motivated and most of them have already developed the capacity to visualize using Mandarin.

Practically, the results of this research can be used by teachers and other educators to contribute to L2 Mandarin teaching or curriculum designs in the following respects: (1) According to the findings, the most compelling reason why participants desire to learn Mandarin is the attraction of Chinese culture. Thus, a teaching curriculum where teachers integrate cultural components into Mandarin language teaching would be a must (2) it is worth noting that Year 8 learners' L2 learning experience and intended effort are not as high as in Year 7. If this represents a tendency, it could 
affect the teaching process and further influence students' achievement in the language in the long term. (3) As learners' intended effort is significantly connected with most of the motivation variables, teachers should always motivate learners using various approaches, especially in relation to cultural interest and travelling, which have a positive prediction effect on intended effort. (4) Teachers could proactively guide learners to practice their visualization, concerning future self-images, to promote their motivation as the results of this study show that vision makes a significant difference to L2 Mandarin learning experience.

\section{References}

Al-Shehri, A. S. (2009). Motivation and vision: The relation between the ideal L2 self, imagination, and visual style. In Z. Dörnyei\& E. Ushioda (Eds.), Motivation, language identity and the L2 self (pp. 164-171). Bristol: Multilingual Matters. Chan, L. (2014). Effects of an imagery training strategy on Chinese university students' possible second language selves and learning experiences. In K. Csize' $r$ \& M. Magid (Eds.), The impact of self-concept on language learning (pp. 357-376). Bristol, UK: Multilingual Matters.

Chen, J. (2010). Introduction: Teaching and learning Chinese in a global era. In J. Chen, C. Wang \& J. Cai (Eds.), Teaching and learning Chinese: Issues and perspectives (pp. ix- xx). NC: Information Age Publishing. Chen, J. F., C. A. Warden, and H. Chang. (2005). Motivators that do not motivate: The case of Chinese EFL learners and the influence of culture on motivation. TESOL Quarterly (pp. : 609-63), Vol.39

Comanaru, R., \& Noels, K. (2009). Self-determination, motivation, and the learning of Chinese as a heritage language. Canadian Modern Language Review (pp.131-158), Vol.66, No1

Csizer, K., \&Kormos, J. (2009). Modelling the Role of Inter-Cultural Contact in the Motivation of Learning English as a Foreign Language. Applied Linguistics, Vol.30, No2

Dörnyei, Z. (1994). Understanding second language motivation: On with the challenge! Modern Language Journal, Vol. 78, No4

Dörnyei, Z. (2001). Motivational strategies in the language classroom. Cambridge: Cambridge University Press.

Dörnyei, Z. (2003). Attitudes, orientations, and motivations in language learning: Advances in theory, research and applications. Language Learning, Vol.53, No1

Dörnyei, Z. (2005). The psychology of the language learner: Individual differences in second language acquisition. Mahwah, NJ: Lawrence Erlbaum.

Dörnyei, Z. (2009). The L2 motivational self-system. In Z. Dörnyei\& E. Ushioda (Eds.), Motivation, language identity and the L2 self (pp. 9-42). Bristol: Multilingual Matters.

Dörnyei, Z. (2010). Questionnaires in second language research: Construction, administration, and processing (2nd Ed.). London: Routledge.

Dörnyei, Z., \& Chan, L. (2013). Motivation and vision: An analysis of future L2 self-images, sensory styles, and imagery capacity across two target languages. Language Learning, Vol.63, No3

Do r̈nyei, Z., Ibrahim, Z., \& Muir, C. (2015). "Directed Motivational Currents": Regulating complex dynamic systems through motivational surges. In Z. Do rnyei, P. D. MacIntyre, \& A. Henry (Eds.), Motivational dynamics in language learning (pp. 95-106). Bristol, UK: Multilingual Matters. 
Dörnyei, Z., \&Kubanyiova, M. (2014). Motivating learners, motivating teachers: Building vision in the language classroom. Cambridge: Cambridge University Press.

Dörnyei, Z., \&Ushioda, E. (2011). Teaching and researching motivation (2nd Ed.). Harlow: Longman.

Higgins, E. T. (1987). Self-discrepancy: A theory relating self and affect. Psychological Review, Vol.94

Kormos, J., Kiddle, T., \&Csize' r, K. (2011). Systems of goals, attitudes, and self-related beliefs in second-language-learning motivation. Applied Linguistics, Vol 32

Kosslyn, S. M., Thompson, W. L., \&Ganis, G. (2006). The case for mental imagery. New York: Oxford University Press.

Gardner, R. C., \& Lambert, W. E. (1959). Motivational Variables in Second-Language Acquisition. Canadian Journal of Psychology, Vol.13, No4

Gardner, R. C., \& Lambert, W. E. (1972). Attitudes and motivation in second-language learning. Rowley, MA: Newbury House.

Gardner, R. C. (1985). Social psychology and second language learning: The role of attitudes and motivation. London: Edward Arnold.

Gardner, R. C. (2001). Integrative motivation and second language acquisition. In Z. Dörnyei\& R. Schmidt (Eds.), Motivation and second language acquisition (pp. 1-19). Honolulu, HI: University of Hawaii Press.

Gardner, R. C. (2006). The socio-educational model of second language acquisition: A research paradigm. In S. H. Foster-Cohen, M. M. Krajnović \& J. M. Djigunović (Eds.), Eurosla Yearbook, Volume 6 (pp. 237-260). Amsterdam, Netherlands: John Benjamins.

Gardner, R. C., \&Smythe, P. C. (1975). Motivation and second-language acquisition. Canadian Modern Language Review, Vol.31

Gass, S. M., \&Selinker, L. (2008). Second language acquisition: An introductory course (3rd ed.). New York, NY: Routledge.

Henry, A. (2010). Gender differences in L2 motivation: A reassessment. In S. Davies (Ed.), Gender gap: Causes, experiences and effects (pp. 81-102). New York: Nova Science.

Henry, A., \&Cliffordson, C. (2013). Motivation, gender, and possible selves. Language Learning, Vol.63

Higgins, E. T. (1987). Self-discrepancy: A theory relating self and affect. Psychological Review, Vol.94

Higgins, E. T. (1998). Promotion and prevention: Regulatory focus as a motivational principle. Advances in Experimental Social Psychology, Vol.30

Johnson, R. B., \&Onwuegbuzie, A. J. (2004). Mixed Methods Research: A Research Paradigm Whose Time Has Come. Educational Researcher, Vol.33, No7

Kim, T. (2009). The sociocultural interface between ideal self and ought-to self: A case study of two Korean students' ESL motivation. In Z. Dörnyei \& E. Ushioda (Eds.), Motivation, language identity and the L2 self (pp. 274-294). Bristol: Multilingual Matters.

Kim, Y. K., \& Kim, T. Y. (2011). The effect of Korean secondary school students' perceptual learning styles and ideal L2 self on motivated L2 behavior and English proficiency. Korean Journal of English Language and Linguistics, 11, 21-42. 
Kim, T. Y. (2009). Korean elementary school students' perceptual learning style, ideal L2 self, and motivated behaviour. Korean Journal of English Language and Linguistics, Vol 9

Lamb, M. (2009). Situating the L2 self: Two Indonesian school learners of English. In Z. Dörnyei\& E. Ushioda (Eds.), Motivation, language identity and the L2 self (pp. 229-247). Bristol: Multilingual Matters.

Liu, Y. (2014). A Study of L2 Chinese Learners' Motivational Self System. Published by ProQuest LLC.

Mackay, J. (2014). Applications and implications of the L2 Motivational Self System in a Catalan EFL context. In K. Csize $r$ \& M. Magid (Eds.), the impact of self-concept on language learning (pp. 377-400). Bristol, UK: Multilingual Matters.

MacIntyre, P. D., Mackinnon, S. P., \&Clément, R. (2009). The baby, the bathwater, and the future of language learning motivation research. In Z. Dörnyei\& E. Ushioda (Eds.), Motivation, language identity and the L2 self (pp. 43-65). Bristol: Multilingual Matters.

Magid, M. (2014). A motivational programme for learners of English: An application of the L2 Motivational Self System. In K. Csize 'r \& M. Magid (Eds.), the impact of self-concept on language learning (pp. 333-356). Bristol, UK: Multilingual Matters.

Morris, T. (1997). Psychological skills training in sport: An overview (2nd ed.). Leeds, UK: National Coaching Foundation.

Morris, T., Spittle, M., \& Watt, A. P. (2005). Imagery in sport. Champaign, IL: Human Kinetics.

Ortega, L. (2009). Understanding second language acquisition. London: Hodder Arnold.

Papi, M. (2010). The L2 motivational self-system, L2 anxiety, and motivated behavior: A structural equation modeling approach. System, 38

Rueda, R., \& Chen, C. B. (2005). Assessing motivational factors in foreign language learning: Cultural variation in key constructs. Educational Assessment, Vol.10, No3

Ryan, S. (2009). Self and identity in L2 motivation in Japan: The ideal L2 self and Japanese learners of English. In Z. Dörnyei\& E. Ushioda (Eds.), Motivation, language identity and the L2 self (pp. 120-143). Bristol: Multilingual Matters.

Ryan, R., \&Deci, E. (2000). Self-determination theory and the facilitation of intrinsic motivation, social development, and well-being. American Psychologist, Vol.55

Ryu Yang, J. S. (2003). Motivational orientations and selected learner variables of East Asian language learners in the United States. Foreign Language Annuals, Vol.36, No1

Sampson, R. (2012). The language-learning self, self-enhancement activities, and self-perceptual change. Language Teaching Research, Vol.16

Skehan, P. (1989). Individual differences in second-language learning. London: Edward Arnold.

Taguchi, T., M. Magid, \& M. Papi. (2009). The L2 motivational self-system among Japanese, Chinese and Iranian learners of English: A comparative study. In Z. Dörnyei and E. Ushioda (eds): Motivation, Language Identity and the L2 Self (pp. 66-97). Multilingual Matters.

Taguchi, N. (2013). Motivation, attitudes and selves in the Japanese context: A mixed methods approach. In M. T. Apple, D. Da Silva, \& T. Fellner (Eds.), Language learning motivation in Japan (pp. 169-188). Bristol, UK: Multilingual Matters.

Wang, A. H. (2010). Motivating U.S. students to learn Chinese as a second language: Understanding the interactions between motivation, ethnicity, and teaching strategies. In J. 
Chen, C. Wang \& J. Cai (Eds.), Teaching and learning Chinese: Issues and perspectives (pp. 117-135). NC: Information Age Publishing.

Watt,N., \& Adams, R. (2013,December 5). David Cameron urges British students to ditch French and learn Mandarin. The Guardian.

Wen, X. (1997). Motivation and language learning with students of Chinese. Foreign Language Annals, Vol.30

Wen, X. (2011). Chinese language learning motivation: A comparative study of heritage and non-heritage learners. Heritage Language Journal, Vol.8, No3

Wen, X. (2013). Chinese language learning motivation: Studies of ethnic background and proficiency level. ShijieHanyuJiaoxue, 2013 No1

Xie, Y. (2011). Representations of L2 motivational self-system with beginning Chinese language learners at college level in the United States: Heritage and non-heritage language learners (Doctoral dissertation). Retrieved from ProQuest Dissertations and Theses database.

You, C. J., \& Chan, L. (2015). The dynamics of L2 imagery in future motivational self-guides. In Z. Dörnyei, P. MacIntyre, \& A. Henry (Eds.). Motivational dynamics in language learning (pp. 397-418). Bristol, UK: Multilingual Matters.

You, C. J., \&Dörnyei, Z. (2016). Language learning motivation in China: Results of a large-scale stratified survey. Applied Linguistics, Vol.37, No4

You, C. J., Dörnyei, Z., \&Csizér, K. (2016). Motivation, vision, and gender: A survey of learners of English in China. Language Learning, Vol.66, No1

Yu, Y. (2009). A study of foreign language learning motivation and achievement: From a perspective of sociocultural theory. CELEA Journal, Vol.32, No3

Yu, B., \& Watkins, D. (2008). Motivational and cultural correlates of second language acquisition: An investigation of international students in the universities of the People's Republic of China. Australian Review of Applied Linguistics, Vol.31, No2 